\title{
Real time monitoring for nowcasting and forecasting ionospheric space weather in Europe with ground digisondes
}

\author{
Anna Belehaki \\ Ionospheric Group, Institute for Space Applications and Remote Sensing, \\ National Observatory of Athens, Palaia Penteli, Greece
}

\begin{abstract}
The Earth's ionosphere largely determines space weather effects on radio wave communications, navigation and surveillance systems. Lately there has been an increasing demand for ionospheric nowcast and accurate forecast services by various groups of users, including European industry. The paper reviews research activities in Europe based on the exploitation of real-time ground digisondes for the provision of nowcasting and forecasting ionospheric space weather information and useful products and services to support operational applications. During the last few years, important progress in databasing, modelling and forecasting ionospheric disturbances based on real-time data from ground digisondes was achieved in the frames of COST Action 271 «Effects of the Upper Atmosphere on Terrestrial and Earth-Space Communications». Further developments are expected to be deployed with the new COST Action 724 on «Developing the basis for monitoring, modelling and predicting space weather», as well as through the Space Weather Pilot Project of the European Space Agency and through projects funded by the European Commission programmes.
\end{abstract}

Key words ionosphere - ionospheric nowcasting ionospheric forecasting - space weather - digisonde ionospheric monitoring networks - ionogram scaling

\section{Introduction}

Knowledge of the state of the upper atmosphere is very important in several applications. The space effects on Radio Frequency (RF) communications and satellite positioning and navigation applications are determined by the ionospheric electron density structure and the Total Electron Content (TEC). Ionosphericspace weather effects can also cause time-vary-

Mailing address: Dr. Anna Belehaki, Ionospheric Group, Institute for Space Applications and Remote Sensing, National Observatory of Athens, Metaxa and Vas. Pavlou str., 15236 Palaia Penteli, Greece; e-mail: belehaki@space.noa.gr ing ionospheric currents causing problems in ground systems such as systems for power generation and supply, oil and gas pipeline distribution, aerial surveying for minerals oil and gas, drilling for oil and gas, railways, especially at the higher latitudes. Lately there has been an increasing interest of the seismic hazards research community in identifying electromagnetic phenomena in the ionosphere as predecessors of seismic events.

Systematic real-time measurements of the ionosphere in Europe are obtained by ground digisondes (Reinisch, 1986) suitable for research and commercial use. The geographic distribution of these digisondes provides almost full coverage of the ionosphere over Europe. These digisondes have the capability of automatically scaling and transmitting in real-time all-important parameters characterising the state of the upper atmosphere and the propagation of radio waves in the ionosphere. At the 

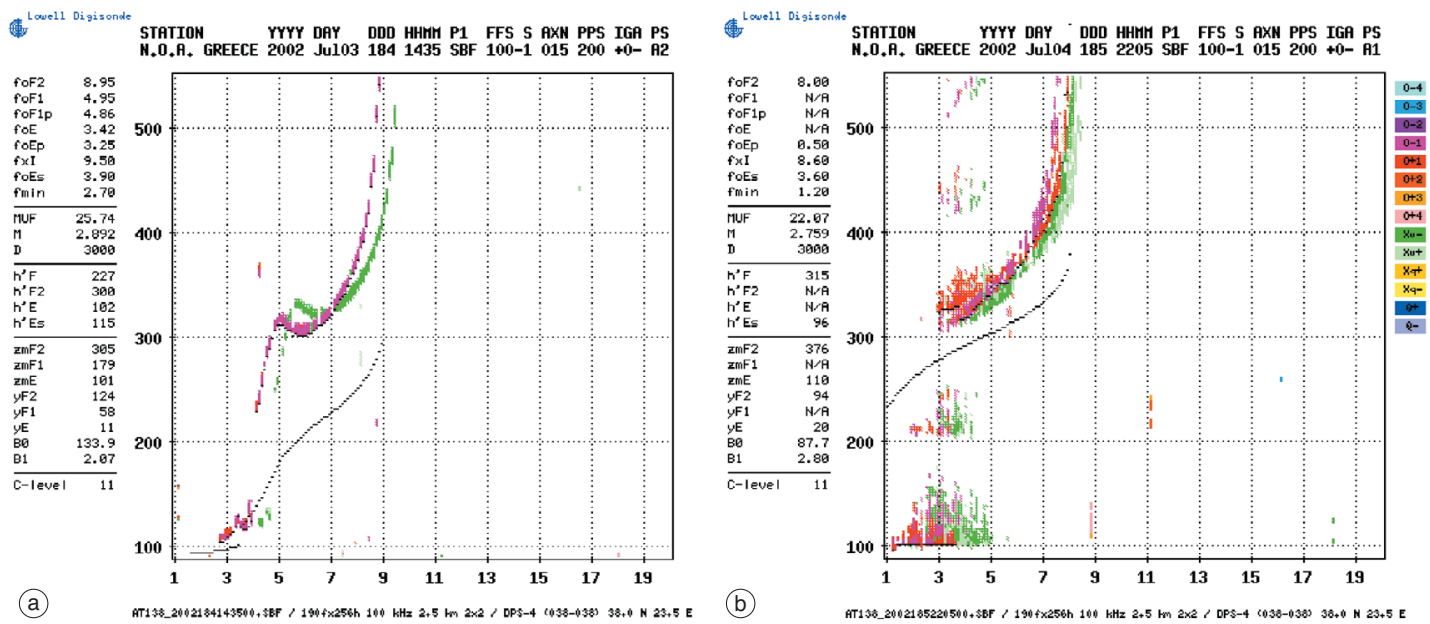

Fig. 1a,b. Ionograms from Athens Digisonde station (a) for the case of undisturbed ionosphere and (b) for a case of spread $F$ appearance.

moment these digisondes operate independently, and knowledge on the state of the ionosphere is generated for a limited area around each station only. This independent operation creates several barriers for transforming this information into usable data, products and services. Considering the increasing demand for upperatmosphere nowcast and forecast services by the scientific community and various commercial users, the need to develop a European network is pressing, especially since similar systems already exist in the US and Australia.

Ground digisondes perform the following operations:

- Automatic scaling of ionograms (with ARTIST software).

- Real-time derivation and transmission of ionospheric parameters (densities and heights of $E$-, $E s-, F 1$-, $F 2$-layers peaks)

- Real-time derivation of electron density profile up to $1000 \mathrm{~km}$ and estimation of the ionospheric electron content (ITEC).

- Real-time derivation of MUF for specific distances.

- Real-time derivation of spread $F$ status.

The performance of the ARTIST automatic scaling software (Reinisch and Huang, 1983), which is integrated to the digisonde computer system, is the key for the exploitation of real- time autoscaling characteristics. The results of the autoscaling program are presented in fig. 1a for the case of undisturbed ionosphere and in fig. $1 \mathrm{~b}$ for the case of spread $F$ appearance. The ARTIST performance is very accurate in both cases.

To better support the previous result, the foF 2 values derived from automatic scaled ionograms from Athens Digisonde are compared with manual validated $f o F 2$ values from the corresponding ionograms for a time period of 11 days (fig. 2a) during which a geomagnetic storm occurred on 24 September 2001 and lasted for three days. It is obvious that the $f o F 2$ values from the automatic scaling follow the manually validated data very closely. Figure $2 b$ shows the differences between the values of foF 2 as scaled by ARTIST and by the manual method from 2019 ionograms recorded at Athens during 20-30 September 2001 as histograms. For the period under study, $97.6 \%$ of the comparisons for $f o F 2$ lay within $\pm 0.5 \mathrm{MHz}$. This agrees with the comparison published by Gilbert and Smith (1988). The distribution is weighted in favor of negative values. This feature results from the effect of interference on the echo trace in the vicinity of $f o F 2$, which often causes premature termination of the ARTIST trace. The same effect appears in the line plot of 
the foF 2 (fig. 2a) as sharp peaks in the automatic scaled $f_{o} F 2$. This effect was also reported by Gilbert and Smith (1988) in their comparison of ARTIST and manual scaled ionospheric parameters observed at Slough. A new version of ARTIST was recently released from the Center of Atmospheric Research of the University of Massachusetts Lowell, and the first results are very promising for successful performance on premature terminated traces (Reinisch, 2003, 2004, pers. comm.).

The accuracy of real-time data, the satisfactory geographic coverage of the European realtime digisondes, and the availability of long term series of historical manual validated data that in some cases cover more than six decades provide the possibility for the development of a system for high quality ionospheric space weather services, for the European Region.

Currently two major research projects are implemented by the European scientific community to study space weather and develop models and forecasting techniques:

- COST271 «Effects of the Upper Atmosphere on Terrestrial and Earth Space Communications» (http://www.cost271.rl.ac.uk), which puts the emphasis on Space Weather effects on Telecommunications (Zolesi and Cander, 2004).

- COST724 «Developing the Scientific Basis for Monitoring, Modelling and Predicting Space
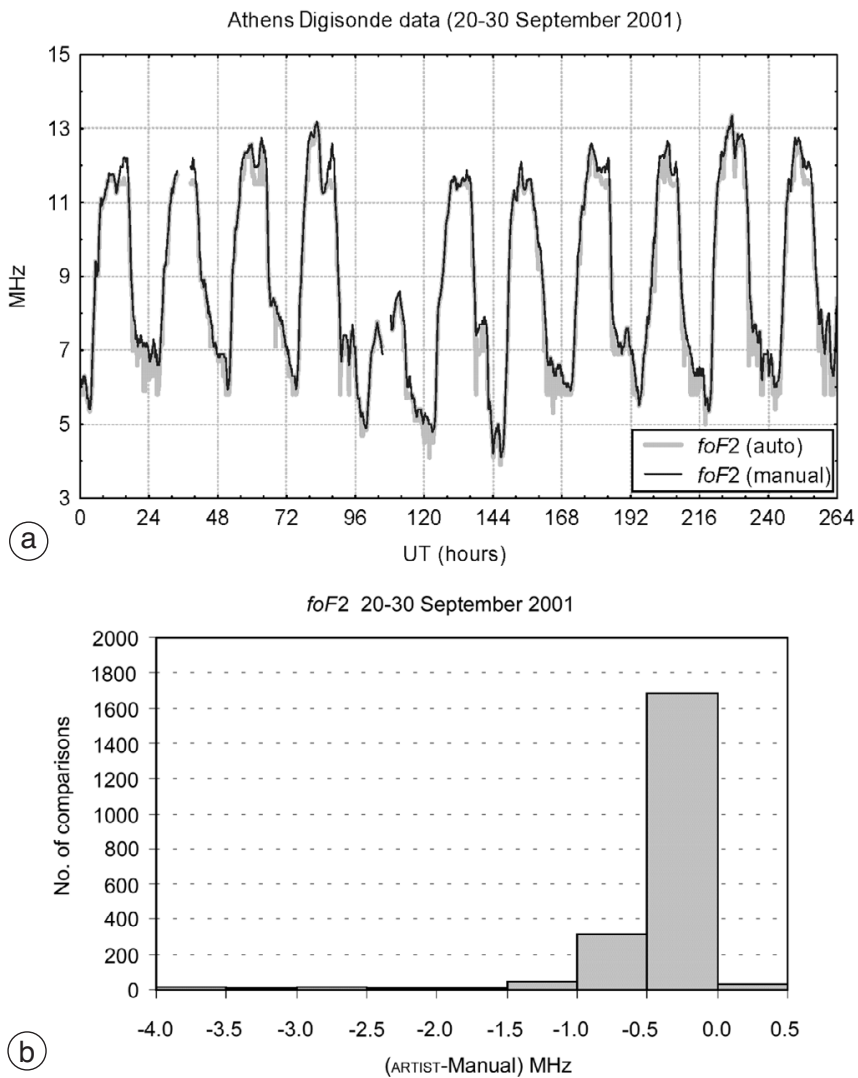

Fig. 2a,b. a) Comparison of automatic scaled (gray line) and manually scaled validated (black line) foF 2 from Athens Digisonde station for a time period of 11 days. b) Differences between the values of $f o F 2$, as scaled by ARTIST and by manual method from 2019 ionograms recorded at Athens during the period 20-30 September 2001. 
Weather» (http://cost724.obs.ujf-granoble.fr), which addresses wider issues in modelling the sun-Earth system (Lilensten et al., 2004).

While COST724 Action is in its initial phase, COST271 is in progress and major efforts have been reported in the development of a comprehensive database of prompt ionospheric parameters for nowcasting and forecasting purposes and of forecasting algorithms to predict the ionospheric and space plasma effects on communications up to a few days ahead of the present.

\section{Nowcasting ionospheric space weather}

One of the most important results of COST271 Action is the development of the Prompt Ionospheric Database at Rutherford Appleton Laboratory (Stamper, 2003). This database receives prompt data on regular basis from the European Digisondes. Developments can be followed at the web site of the database $<$ http://www.wdc.rl.ac.uk/cgi-bin/digisondes/ cost_database.pl>. This tool can be used by researchers to access prompt and past ionospheric data from several European stations. Besides this basic tool, noticeable progress has been reported during the last few years, developed mainly in the frames of COST271 Action and of the ESA Pilot Space Weather Project, aiming to map the ionospheric characteristics in realtime over Europe and to monitor and forecast the space environment including the ionosphere and plasmasphere.

\subsection{Ionospheric mapping}

The effective use of automatic scaled ionospheric parameters derived from ground digisondes was demonstrated in the frames of COST271 Action and the ESA Pilot Space Weather Project with the development of a method for real-time mapping of the state of the ionosphere over Europe, proposed by Zolesi et al. (2003). The objective of the proposed method is to update the Simplified Ionospheric Regional Model (SIRMUP) in real-time using automatic scaled ionospheric data from the four European Digisondes operated in Athens,
Rome, Juliusruh and Chilton. The achieved result is monitoring the state of the ionosphere over Europe with sufficient accuracy to be of use from earth-space communications and navigation systems (as GALILEO).

SIRM (Zolesi et al., 1993) provides ionospheric parameters that represent monthly median values and vary as a function of geographic location, local time, and $R_{12}$. The updated SIRM (SIRMUP) takes as input the real-time automatic scaled values from the four Digisondes to compute an effective sunspot number $\left(R_{\text {eff }}\right)$ that the method is using instead of $R_{12}$.

$R_{\text {eff }}$ is the sunspot number for which

$$
\frac{1}{n} \sum_{i=1}^{n}\left(f o F 2_{\text {obsi }}-f o F 2_{\text {calci }}\right)^{2}=\min
$$

where $n$ is the number of the reference stations, $f o F 2_{\text {obsi }}$ is the observed foF 2 at the reference station $i, f o F 2_{\text {calc } i}$ is the calculated foF 2 from SIRM at the coordinated of the reference station $i$.

To test the reliability of the method, the relative errors (Houminer et al., 1993) between the observed values (manually validated) at some test stations and the calculated foF 2 values by the model, were determined using the following equations:

$$
\begin{gathered}
e 1=\frac{\left|f O F 2_{\text {obs }}-f o F 2_{\text {SIRM }}\right|}{f O F 2_{\text {obs }}} \\
e 2=\frac{\left|f O F 2_{\text {obs }}-f o F 2_{\text {SIRMUP }}\right|}{f O F 2_{\text {obs }}}
\end{gathered}
$$

where $f_{O F} 2_{\text {obs }}$ is the observed $f_{o F} 2$ at the test station, foF $2_{\text {SIRM }}$ is the SIRM calculated foF 2 at the test station using the observed $R_{12}$ sunspot number, and $f o F 2_{\text {SIRMUP }}$ is the SIRMUP calculated foF 2 at the test station using $R_{\text {eff }}$.

According to the above description, when the criterion

$$
e 2<e 1
$$

is valid, the method of real-time updating is successful in the sense that the resulting map in the specific area is more representative of the real ionosphere than the corresponding map resulting from the use of monthly median values. 
The performance of SIRMUP method was tested by Zolesi et al . (2004) under all possible ionospheric conditions, including quiet intervals, largescale disturbances such as storm negative phases and daytime positive effects of long duration as well as small-scale effects such as Travelling Atmospheric Disturbances (TADs) and nighttime positive effects, by presenting simulation results for several time intervals. An indicative interval is presented in fig. 3 for the storm period of 16 to 24 August 2001. The storm started with an initial compression phase in Dst observed on 17 August 2001 at 12:00 UT. The European region was already in the noon sector and therefore was affected by TADs, causing the strong daytime positive effect, which was observed from Sofia during local afternoon hours. At 22:00 UT, Dst reached its minimum and consequently the recovery phase started, although considerable substorm activity was recorded by the $A E$-index (not shown) until midnight. It is possible that this substorm activity caused the generation of a new composition dis- turbance zone (Tsagouri et al., 2000), producing the strong negative phase in the early hours of the 18 August. Consequently, the adjacent TADs generated in the daylight sector probably caused the noticeable positive effect in the morning sector. As the geomagnetic activity recovered in the following days, there was a remaining ionospheric disturbance recorded in Sofia of small magnitude. An intense substorm activity recorded by the $A E$ index from the morning of 21 August until noon of 23 August produced TAD's on the 21 and 22 August in the daylight sector and a noticeable negative phase on 23 August. Most of the time the quantity $e 1-e 2$ was positive indicating that the performance of SIRMUP was particularly successful during periods of large scale ionospheric disturbances causing the negative effects recorded on the 18 and 23 August 2001, as well as small scale ionospheric disturbances generated by TADs on 17 August 2001.

In the following the performance of the SIRMUP model is presented during the relatively

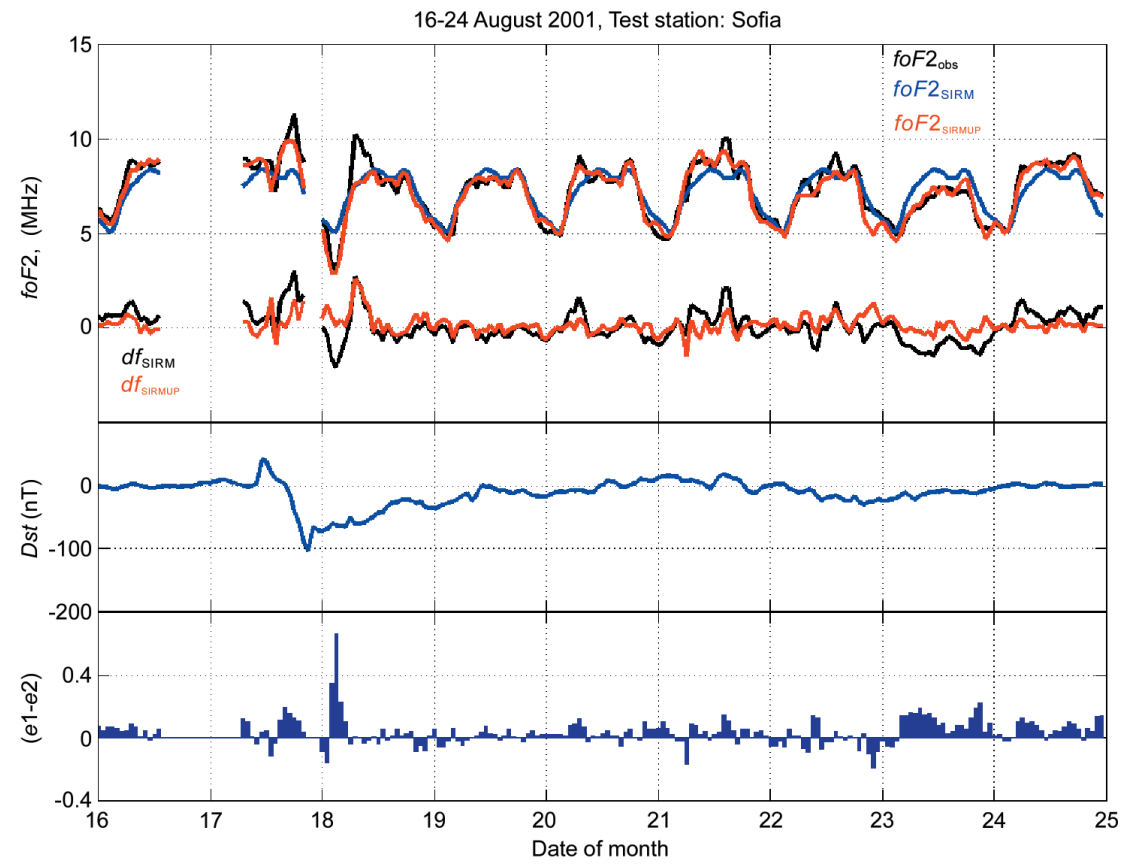

Fig. 3. Simulation results for the storm period 16-24 August 2001 at the test station in Sofia. 
quiet geomagnetic interval from 6 to 10 December 2001. The simulation results are presented in fig. 4 for Sofia test station. During this period a different type of ionospheric activity was observed, caused probably by changes in the global wind circulation (Prölss, 1995), which resulted in the considerable increase in the foF 2 value during day hours, for the first three days of the interval. Although the Dst-index did not present any disturbance, the source

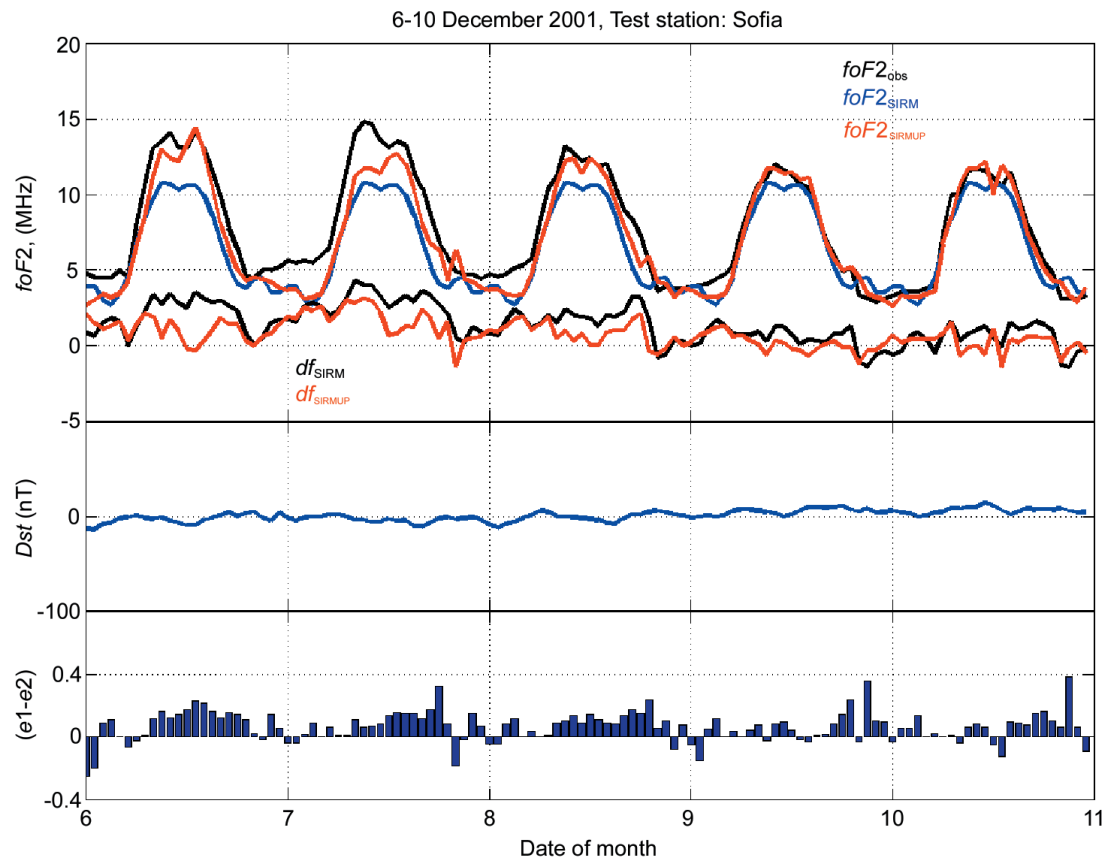

Fig. 4. Simulation results of the quiet period 6-10 December 2001 at the test station in Sofia.
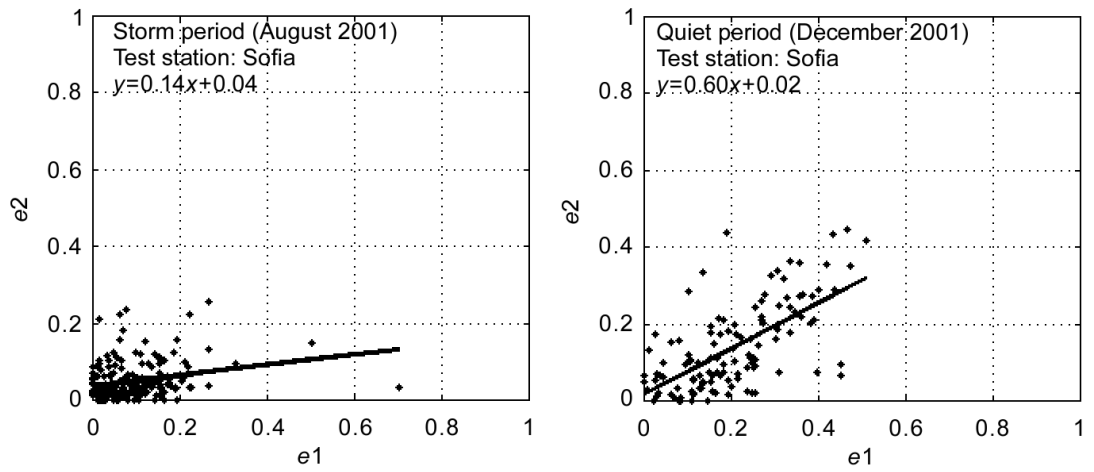

Fig. 5. The scatter plots of $e 2$ versus $e 1$ for the two simulated time periods. The best-fit line and its equation are also shown. 
of the observed ionospheric disturbance is the continuous substorm activity recorded by the $A E$-index. From the inspection of the differences between the relative errors $(e 1-e 2)$ plotted in the bottom of fig. 4 it is concluded that SIRMUP performance is particularly successful during large-scale positive effects observed on the first three days of this interval. During nighttime positive effects the performance is worse but still better than SIRM.

To obtain a quantitative estimate of the SIRMUP performance, the scatter plots of $e 2 \mathrm{ver}$ sus $e 1$ are shown in fig. 5 for the two simulated time periods. The best-fit line is overplotted in each diagram. In both cases the criterion $e 2<e 1$ is statistically satisfied. Especially for the disturbed period (August 2001) a significant improvement in the mapping performance is noted since $e 2$ is much smaller than $e 1$. Nevertheless this is not the case for the quiet period (December 2001) as well, since the high correlation between the two error values $e 1$ and $e 2$ indicate an almost equivalent performance of the two mapping techniques.

Overall, the results presented by Zolesi et al. (2003) show a significant improvement of SIRMUP performance comparing to SIRM, during quiet intervals and also during large-scale ionospheric disturbances. A marginal improvement during localised ionospheric disturbances is also reported.

This very detailed analysis demonstrates that the use of real-time automatic data can improve existing mapping techniques in order to be useful for operational applications.

\subsection{Use of ITEC parameter for nowcasting the ionospheric and plasmaspheric electron content}

Another service that could be generated from the exploitation of real-time digisondes is the real-time availability of the ionospheric electron content (ITEC). Total Electron Content (TEC) is a key parameter that describes the major impact of the ionized atmosphere on the propagation of radio waves, which is crucial for terrestrial and Earth-space communications including navigation satellite systems such as
GPS, GLONASS, and the future GALILEO system. A standard technique to determine TEC is from dual frequency GPS (Global Positioning System) measurements. This technique measures the electron content along a slant signal path, from which a vertical TEC is estimated by simple geometric corrections (see for example Jakowski, 1996). As the orbit altitude of GPS satellites is $\sim 20000 \mathrm{~km}$, GPS derived TEC corresponds to the total electron content (bottomside and topside ionosphere, and plasmasphere) and it is sensitive to topside ionospheric and plasmaspheric processes.

Recently, Reinisch and Huang (2001) proposed a new technique to determine the vertical ionospheric electron content from groundbased ionogram measurements. The ionogram provides the information to directly calculate the vertical electron density profile up to the peak of the $F 2$-layer. The profile above the peak is approximated by an $\alpha$-Chapman function with a constant scale height $H_{T}$ derived from the bottomside profile shape at the $F 2$ peak, according to the equation

$$
N_{T}=N m F 2 \exp \left[\frac{1}{2}\left(1-z-e^{-z}\right)\right]
$$

where $z=(h-h m F 2) / H_{T}, N m F 2$ is the maximum electron density and $h m F 2$ the height of the $F 2$-layer peak. The ionosonde TEC, or ITEC, is then calculated as an integral from 0 to $\sim 1000$ $\mathrm{km}$ over the entire profile.

From the above definition it is obvious that ITEC is not equivalent to the GPS derived TEC parameter (GPSTEC). Since the ITEC parameter could develop into a very useful tool for nowcasting ionospheric space weather, it is important to determine with accuracy the relationship between ITEC and TEC. A preliminary ITEC validation based on case studies was performed by comparing ITEC with TEC values derived from GPS, incoherent scatter radar, and geostationary satellite beacon measurements at middle latitudes and with TOPEX measurement at the equator (Reinisch and Huang, 2001; Belehaki and Tsagouri, 2002a). It was shown that ITEC is generally within $\sim 10 \%$ of the satellite TEC. As a first approach the difference between GPSTEC and ITEC may be interpreted as the plasmaspheric content, but this interpretation needs to 

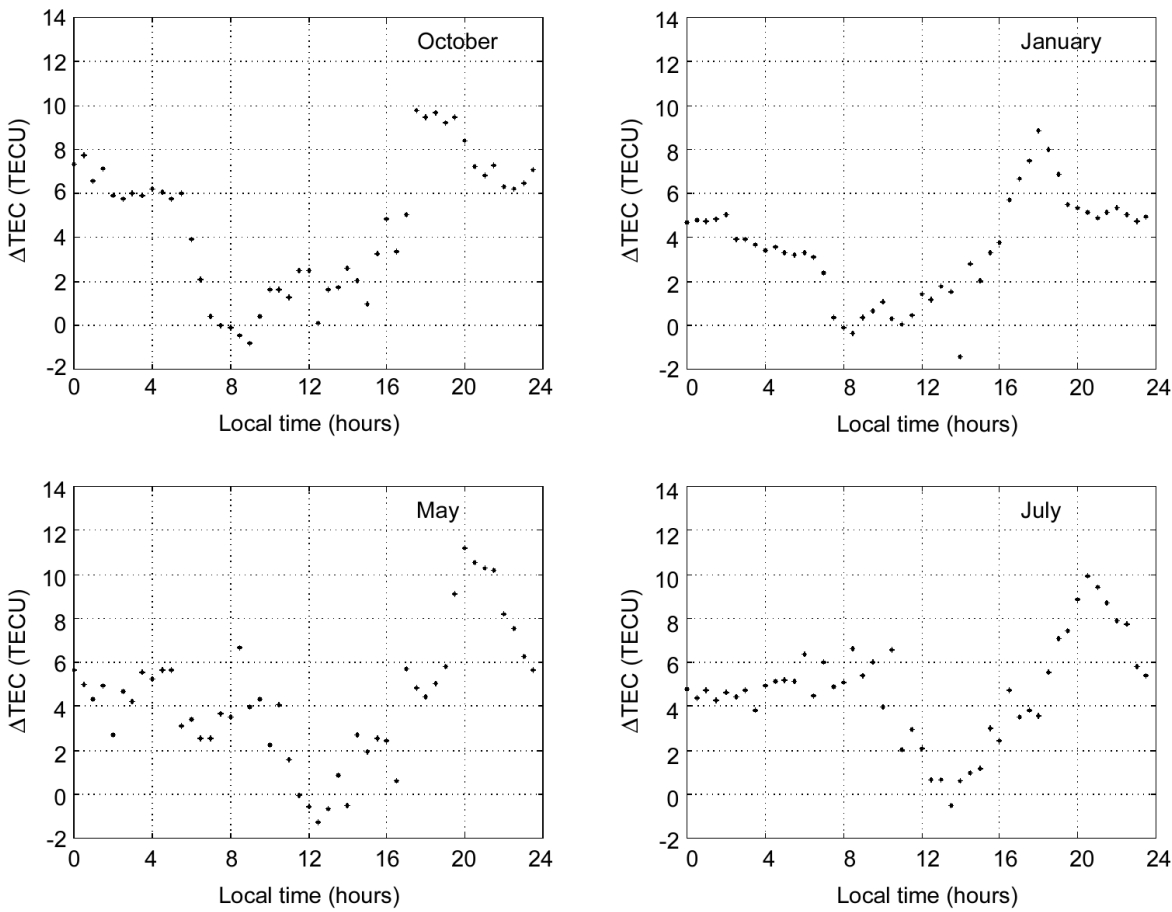

Fig. 6. The daily variation of the monthly median values of $\triangle \mathrm{TEC}$ over four months. A morning minimum and an evening maximum characterize the daily variation of $\triangle \mathrm{TEC}$.

be verified on a statistical basis (Reinisch et al., 2001; Belehaki and Jakowski, 2002).

Recently, Belehaki et al. (2003) presented a systematic analysis of the ITEC values from digisonde measurements at Athens and of GPSTEC data from TEC maps produced by the German Aerospace Center (DLR/IKN) for Europe using GPS measurements, for Athens coordinates. It was shown that the residuals of the two independent quantities, $\triangle \mathrm{TEC}$, provide qualitative information on the plasmaspheric dynamics as deduced from their diurnal and seasonal behavior and their variation during geomagnetic storms and this conclusion is based on three findings: a) in general, the daily variations of electron content above $1000 \mathrm{~km}$ for Athens have the same qualitative characteristics as the plasmaspheric content daily variation (fig. 6). There is some diurnal interchange between the ionosphere and plasmasphere with

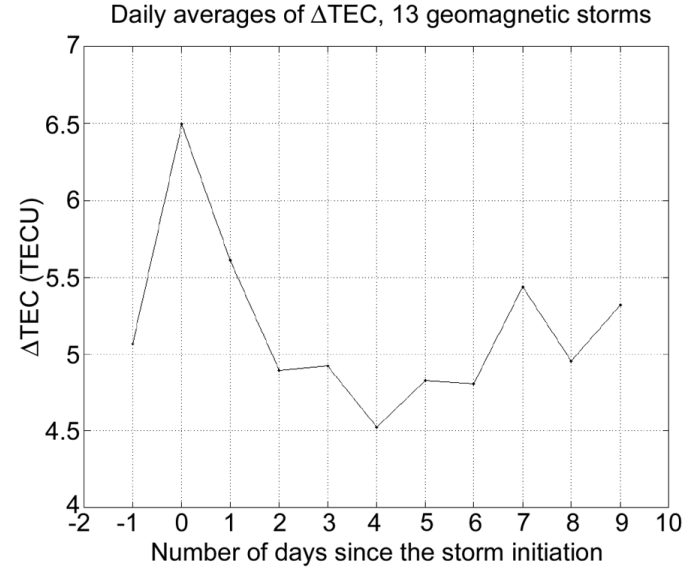

Fig. 7. Superposed epoch analysis on 13 geomagnetic storms of the daily averages of the difference between GPSTEC and ITEC as a function of number of days since storm initiation. 

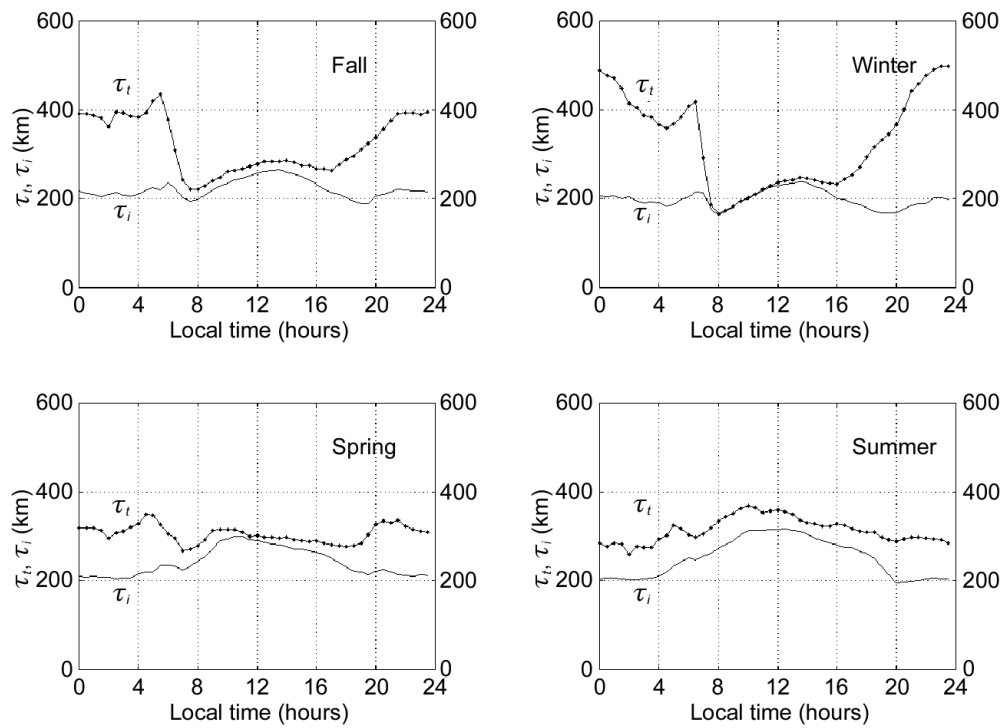

Fig. 8. The daily variation pattern of the slab thickness parameters $\tau_{t}$ (black-dotted line) and $\tau_{i}$ (black-solid line) at Athens, extracted from the monthly median values, for the four seasons.

downward diffusion from the latter helping maintain the nighttime F2-layer (Lunt et al., 1999; Belehaki and Tsagouri, 2002b) and daytime refilling. The evening peak in $\triangle \mathrm{TEC}$ residuals, which is the striking feature in $\triangle \mathrm{TEC}$ variation over Athens and is also observed over Chilton, is attributed to the evening plasmaspheric bulge. b) The effect of geomagnetic activity in $\triangle$ TEC residuals, presented in fig. 7 , is qualitatively the same as the effect on the plasmasphere, showing a drastic depletion immediately after the start of the storm and a consequent replenishment that lasts for 9 days. c) The daily variation of the ionospheric slab thickness $\left(\tau_{i}=\right.$ ITEC $\left./ N m F 2\right)$ is compatible with the variation of the daytime thermospheric temperature (fig. 8). There is, however, a significant nighttime increase in the total slab thickness $\left(\tau_{t}=\right.$ $=$ GPSTEC $/ N m F 2$ ), which is most prominent in winter and is due to the lowering of the $\mathrm{O}^{+} / \mathrm{H}^{+}$ transition height.

The study demonstrates that the ITEC parameter is a qualitative measure of the ionospheric electron content and that comparing the ionosonde derived TEC (ITEC) with GPS derived TEC (GPSTEC) at a given location it is pos- sible to estimate experimentally the effect of the plasmasphere on GPS measurements.

As a next step, in order to determine the quantitative relation between the ITEC parameter and the Total Electron Content a statistical study was recently presented by Belehaki and Kersley (2003) using Incoherent Scatter Radar (ISR) profiles from Malvern site $\left(52.1^{\circ} \mathrm{N}\right.$, $\left.2.3^{\circ} \mathrm{W}\right)$. The TEC estimates from ISR profiles were compared with ITEC estimates, extracted from the same profiles, computed by extrapolating the bottomside ISR electron density profile to the topside according to the method proposed by Reinisch and Huang (2001). A case showing the results of the topside extrapolation of the bottomside ISR ionograms is presented in fig. 9.

The first results from the comparison study between TEC (from ISR profiles) and ITEC (computed from the extrapolated ISR profiles using the $H-R$ method) are presented in fig. 10. Here the statistics are limited to 317 cases of daytime profiles and 368 cases of nighttime profiles.

In summary, the results show a very good agreement especially during nighttime hours and support the original derivation of the ITEC as a measure of the ionospheric electron con- 


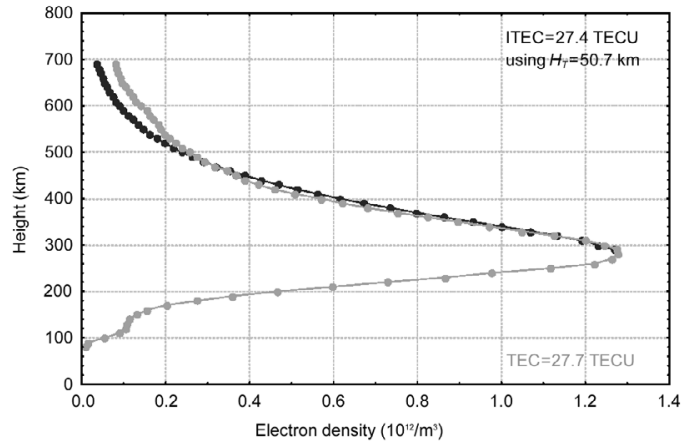

Fig. 9. Comparison between the ISR profile (gray line) and the extrapolated topside profile after the Huang and Reinisch (2001) method. The resulted total electron content is also noted.

Malvern - 1968 (daytime profiles no. $=317$ ) $y=2.83+0.874^{*} x$

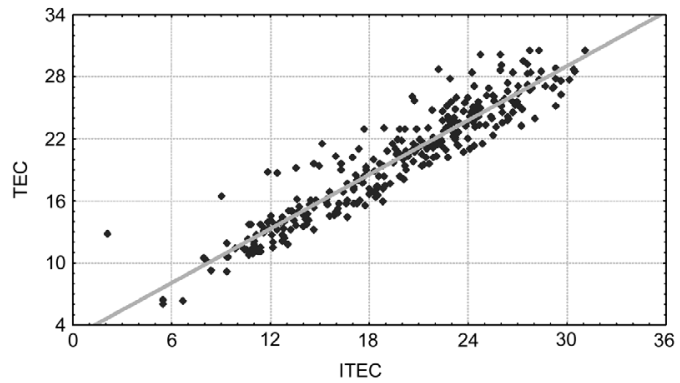

Malvern - 1968 (nighttime profiles no. $=368$ ) $y=-0.441+0.993^{*} x$

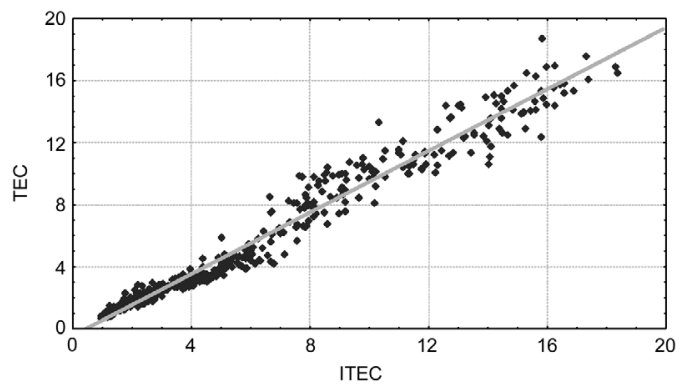

Fig. 10. Statistical results from the comparison between TEC (from ISR profiles) and ITEC (computed from the extrapolated ISR profiles using the $H-R$ method) for daytime cases (upper panel) and nighttime cases (bottom panel). tent. Statistical analysis over the whole sample of 4000 profiles is needed before extracting final conclusions.

\section{Forecasting ionospheric space weather}

Systematic ionospheric space weather forecasts are provided by the Rutherford Appleton Laboratory (http://ionosphere.rcru.rl.ac.uk) using the Short-Term Ionospheric Forecasting (STIF) tool for the European Region based on continuous monitoring of the ionosphere (Cander, 2003). This operational system provides forecasting maps for up to $24 \mathrm{~h}$ ahead and archive measurement maps of the critical frequency of ionospheric F2-layer $f o F 2$, the Maximum Usable Frequency for a $3000 \mathrm{~km}$ range $\operatorname{MUF}(3000) F 2$, NeQuick modelled vertical Total Electron Content (TEC) and Frequency of Optimum Traffic (FOT) for the area of interest at each UT hour. Accuracy of forecast of $f_{o F}, \operatorname{MUF}(3000) F 2$ and TEC has been studied through several statistical comparisons between measured and forecast values of foF 2 and $\operatorname{MUF}(3000) F 2$. These results clearly suggest that STIF tool is a very reliable forecasting technique in relatively quiet geomagnetic conditions. Although these conditions prevail in the normal Earth's ionosphere, the conditions during the geomagnetic storms are of more importance for current and future radio communications services as well as space weather operational requirements and scientific studies and under such conditions STIF has been proved inadequate (Cander et al., 2002).

A new approach to forecast ionospheric space weather is attempted based on the idea that solar wind disturbances can determine the timing and the magnitude of ionospheric disturbances (Belehaki and Tsagouri, 2002b), with the primary goal to develop the understanding and the means to forecast how the ionospheric F2-layer will respond to abruptly and dramatically changing solar and geomagnetic conditions.

Real-time measurements of the critical frequency of the $F 2$-layer, $f_{O} F 2$, and the propagation factor for a $3000 \mathrm{~km}$ range, $M(3000) F 2$ from four European Digisondes operating in Athens, Rome, Chilton and Juliusruh and being available from WDC-C1 at RAL (http://www.wdc.rl.ac.uk/cgi- 


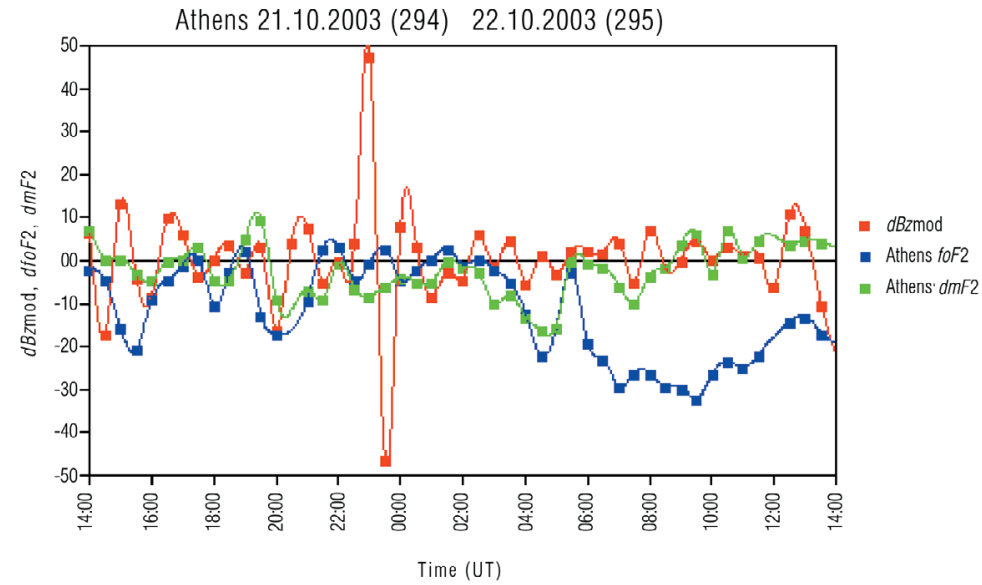

Fig. 11. Bz-IMF rate of change over the preceding $30 \mathrm{~min}$ interval, with the corresponding percentage deviation from the median of $f o F 2, d f o F 2(\%)$, and percentage deviation from the median of $M(3000) F 2, d m F 2(\%)$, for Athens Digisonde.

bin/digisondes/cost_database.pl) and the Bz-component of the interplanetary magnetic field, $B z-$ IMF, from NASA Advanced Composition Explorer (ACE) spacecraft mission (http://sec.noaa.gov/ Data) are combined for the development of a real-time dynamic system, oriented to monitor the ionospheric propagation conditions over Europe. Currently such an automated data analysis at 30 min intervals is operational at RAL $<$ http://ionosphere.rcru.rl.ac.uk>.

The latest charts show the modified $B z$-IMF rate of change over the preceding 30 min interval, with the corresponding percentage deviation from the median of $f o F 2, d f o F 2(\%)$, and percentage deviation from the median of $\mathrm{M}(3000) F 2, d m F 2(\%)$, for Juliusruh, Chilton, Rome and Athens ionosonde stations.

A very representative example is shown in fig. 11, where after a very strong disturbance in the $B z$ component of the IMF at midnight, a strong ionospheric depletion is observed over Athens with a time delay of $3 \mathrm{~h}$.

The presented facility is available for both operational purposes and scientific studies. Future developments will include the introduction of other solar wind parameters from ACE such as the rate of change of solar wind number density $(d n / d t)$, and the rate of change in solar wind bulk speed velocity $(d U / d t)$ to fully monitor solar-terrestrial conditions in purpose to issue a preliminary warning. Moreover, the statistical analysis of the future results could help in modelling and forecasting the ionospheric response during storm conditions few hours ahead, which is of crucial importance for the reliable performance of technologically advanced radio communications systems under disturbed propagation conditions (Johnson et al., 1997), since the ionospheric forecasting models currently in operation have shown a high degree of reliability during quiet conditions, but have been proved inadequate during storm events (Cander et al., 2002).

\section{Conclusions}

Significant progress has been reported during the last few years by the European ionospheric community towards the development of tools and models for the nowcasting and forecasting ionospheric space weather based on real-time measurements acquired from European Digisondes. Most of this progress is part of the COST271 Action and of the ESA Space Weather Pilot Project. The new staring COST724 Ac- 
tion will contribute in this direction, improving our basic knowledge on space weather modelling and forecast.

Europe has the major advantage of possessing modern ionospheric stations capable of providing in real-time accurate automatic scaled ionospheric parameters that characterize the propagation of radiowaves (Cander et al., 2004). The existing digisondes are reliable, operate on a continuous basis and their geographic distribution provides an almost full coverage of the $\mathrm{Eu}-$ ropean region. The systematic exploitation of automatic validated ionospheric data from the network of real-time digisondes in Europe can i) lead to the development of space weather, communications, navigation models; ii) improve our understanding of the physical processes involved in the ionosphere and plasmasphere; iii) lead to the development of an operational system for nowcasting and forecasting the state of the ionosphere over Europe.

An important step in this direction can be achieved through the successful implementation of DIAS project (European Digital Upper Atmosphere Server). DIAS is a project co-funded by the European Commission eContent programme, and has as the main objective to develop a pan-European digital data collection on the state of the upper atmosphere, based on real-time information and historical data collections provided by most operating ionospheric stations in Europe. DIAS system will distribute the information required by various groups of users for the specification of upper atmospheric conditions over Europe suitable for nowcasting and forecasting purposes. The successful operation of DIAS system will lead to the development of new European added-value products and services and to the effective use of observational data in operational applications. The participating institutes working on the acquisition, processing, storage and dissemination of data and services and on the development of the technological system are the National Observatory of Athens, the Rutherford Appleton Laboratory, the Istituto Nazionale di Geofisica e Vulcanologia, the Swedish Institute of Space Physics, the Leibniz Institute of Atmospheric Physics, the Space Research Centre of the Polish Academy of Science, and the Department of Informatics and Telecom- munications of the University of Athens. The official web site can be accessed in the address $<$ http://www.iono.noa.gr/DIAS $>$. Finally it is our belief that the successful operation of the DIAS server planned to start in February 2006, will contribute, as a Europe-wide effort, to the development of a facility for the extensive use of ground-based ionospheric observations.

\section{Acknowledgements}

The author of this paper would like to express her gratitude to the conveners of the EGS2003 session ST17 «Effects of the Ionosphere on Terrestrial and Earth-Space Communications», Dr. Bruno Zolesi and Dr. Ljiljana Cander for their kind invitation to present this review talk. This work is part of the European COST271 Action and was partly supported by the ESA Space Weather Pilot project «GIFINT» and by the NATO grant EST.CLG.979784.

\section{REFERENCES}

Belehaki, A. and N. Jakowski (2002): Studies of the ionospheric ionization over Athens using ground ionosonde and GPS derived TEC values, Acta Geod. Geophys. Hung., 37 (2-3), 163-170.

BELEHAKI, A. and L. KERSLEY (2003): Statistical validation of the ITEC parameter, in Third Workshop of the COST271 Action, 23-27 September 2003, Spetses, Greece.

BeleHAKI, A. and I. Tsagouri (2002a): Investigation of the relative bottomside/topside contribution to the Total Electron Content estimates, Ann. Geophysics, 45 (1), 73-86.

Belehaki, A. and I. Tsagouri (2002b): On the occurrence of storm-induced nighttime ionisation enhancements at ionospheric middle latitudes, J. Geophys. Res., 108 (A8), doi:10.1029/2001JA005029.

BeleHAKI, A., N. JAKOWSKI and B. W. Reinisch (2003): Comparison of ionospheric ionization measurements over Athens using ground ionosonde and GPS derived TEC values, Radio Sci., 38 (6), 1105, doi:10.1029/ 2003RS002868

CANDER, LJ.R. (2003): Toward forecasting and mapping ionospheric space weather under the COST actions, Adv. Space Res., 31 (4), 957-964.

CAnder , LJ.R., I. Tsagouri and A. BelehaKi (2002): A real-time dynamic system to forecast ionospheric storm effects in middle latitudes, in Proceedings of the ESA Space Weather Workshop, Space Weather Applications Pilot Project (on line http://www.estec.esa.nl/wmwww/ spweather/workshops/spw_w4/proceedings/LC_paper.pdf), December 2002, ESTEC, Noordwijk, The Netherlands. 
CANDER L., J. Hickford, I. TSAgouri and A. BelehaKi (2004): Real-time dynamic system for monitoring the ionospheric propagation conditions over Europe, Electr. Lett., 40 (4), 224-226.

GILBERT, J.D. and R. SMith (1988): A comparison between the automatic ionograms scaling system ARTIST and the standard manual method, Radio Sci., 23 (6), 968-974.

Houminer, Z., J.A. Bennet and P.L. Dyson (1993): Realtime ionospheric model updating, J. Electr. Electron. Eng., Aust., 13 (2), 99-104.

JAKOWSKI, N. (1996): TEC monitoring by using satellite positioning systems, in Modern Ionospheric Science, edited by H. KoHL, R. RÜsTER and K. SchlEgEL (Katlenburg-Lindau, FRG), 371-390.

Johnson, E.E., R.I. Desourdis, G.D. Earle, S.C. Cook and J.C. OstergaArd (1997): Advanced High-Frequency Radio Communications (Artech House, Boston and London, USA), pp. 376.

Lilensten J., T. ClaRK and A. BelehaKi (2004): Europe's first space weather think tank, Space Weather, 2 (4), S04001, 10.1029/2003SW000021

LunT, N., L. KeRsLey and G.J. BAILEY (1999): The influence of the protonosphere on GPS observations: model simulations, Radio Sci., 34 (2), 725-732

PröLss, G.W. (1995): Ionospheric $F$-region storms, in Handbook of Atmospheric Electrodynamics, edited by H. Volland (CRC Press, Boca Raton, Fla.), vol. II, 195-248.

REINISCH, B.W. (1986): New techniques in ground based ionospheric sounding and studies, Radio Sci., 21 (3), 331-346.
ReINISCH, B.W. and X. HuAng (1983): Automatic calculation of electron density profiles from digitalionograms, 3. Processing of bottomside ionograms, Radio Sci., 18, 477-492.

Reinisch, B.W. and X. Huang (2001): Deducing topside profiles and total electron content from bottomside ionograms, Adv. Space Res., 27 (1), 23-30

Reinisch, B.W., X. Huang, A. Belehaki and J.-C. Jodogne (2001): Bottom and topside ionospheric TEC obtained from ground-based ionosonde measurements, in Proceedings of the International Beacon Satellite Symposium, Boston College, MA.

STAMPER, R. (2003): The COST271 Action - Databasing and validating prompt ionospheric parameters, Third Workshop of the COST271 Action, 23-27 September 2003, Spetses, Greece.

Tsagouri, I., A. Belehaki, G. Moraitis and H. MavroMICHALAKI (2000), Positive and negative ionospheric disturbances at middle latitudes during geomagnetic storms, Geophys. Res. Lett., 27, 3579-3582.

ZOLESI, B. and LJ.R. CANDER (2004): COST271 Action Effects of the upper atmosphere on terrestrial and Earth-space communications: introduction, Ann. Geophysics, 47 (suppl. to no. 2/3), 915-925.

Zolesi, B., Lu.R. CANDER and G. DE FranCESCHI (1993): Simplified ionospheric regional model for telecommunication applications, Radio Sci., 28 (4), 603-612.

Zolesi, B., A. Belehaki, I. Tsagouri and Lj.R. CAnder (2004): Real-time updating of the simplified ionospheric regional model for operational applications, $R a$ dio Sci., 39 (2), RS2011, 10.1029/2003RS002936. 